\title{
OUTCOMES OF CORNEAL COLLAGEN CROSS LINKING IN PEDIATRIC KERATOCONUS IN UPPER EGYPT
}

\author{
Zidan, M. ${ }^{(*)}$, Mounir, A., Farouk, M. \& Radwan, G. \\ Ophthalmology dept., Faculty of Medicine, Sohag Univ., Sohag, Egypt \\ *E-mail: meer.zidan2017@gmail.com
}

Received 18/3/2020

Accepted 28/5/2020

\begin{abstract}
Purpose: To assess the short term visual, refractive, and tomographic outcomes of corneal collagen cross-linking (CXL) in pediatric patients with keratoconus. Patients and Methods: A prospective interventional non-comparative case series study that was conducted in The Future Center for refractive surgery, Sohag, in the period from May 2017 to October 2018, All the eyes were treated with accelerated trans-epithelial corneal cross-linking under topical or general anesthesia and the following data were collected at baseline, 3 months, 6 months, and 12 months postoperatively for all patients: uncorrected- and best-corrected visual acuity, sphere, spherical equivalent, cylinder, and tomographic findings. Results: A total of 50 eyes of 25 patients, 16 males (64\%) and 9 females $(36 \%)$ were included. Mean age at surgery was $15.76 \pm 1.67$ years (range, 13-18). Mean uncorrected visual acuity was $0.83 \pm 0.30 \log M A R$ at baseline and $0.74 \pm 0.33 \log M A R$ at 12 months $(P=0.009)$. Mean preoperative best-corrected visual acuity was $0.52 \pm 0.28$ logMAR, which improved to $0.31 \pm 0.27$ logMAR at 12 months $(P<0.0001)$. Mean sphere was $-3.17 \pm 3.95$ at baseline and improved to $-2.75 \pm$ 3.55 at 12 months $(P=0.01)$. Mean cylinder was $-3.12 \pm 2.25$ preoperatively and improved to $-2.71 \pm$ 2.56 at 12 months $(P=0.052)$. Baseline spherical equivalent was $-4.69 \pm 4.48$ which improved to $-4.08 \pm$ 4.30 at 12 months $(P=0.003)$. Mean baseline Kmax, Kmin, and Kmean values were 48.31 \pm 3.92 , $44.48 \pm 2.73,46.07 \pm 2.87$ respectively; these values were stable at 12 months $(P>0.05)$. There was non-significant reduction in the mean thinnest corneal area from baseline $(453.36 \pm 40.50 \mathrm{~mm})$ to 12 months $(447.84 \pm 46.51 \mathrm{~mm}),(P=0.06)$. There were no significant postoperative complications. One case show progression at the $12^{\text {th }}$ month as the followings were noticed; The cylinder increased from -7.00 to -10.50 , The flattest $K$ increased from $55 D$ to $59 D$, The steepest $K$ increased from $58 D$ to $61 \mathrm{D}$, the corneal thickness at thinnest location decreased from $400 \mu \mathrm{m}$ to $381 \mu \mathrm{m}$. Conclusion: In this study CXL effectively stabilized keratometry values at 12 month, while improving uncorrected visual acuity, best corrected visual acuity, and refractive indices.
\end{abstract}

Keywords: Corneal collagen cross-linking, Pediatric Keratoconus, Upper Egypt

\section{Introduction}

Keratoconus is characterized as a bilateral, non symmetrical and non inflammatory, progressive corneal ectasia [1]. Visual impairment results from progressive myopia, and irregular astigmatism which caused by progressive corneal thinning and protrusion. It usually starts at puberty and stabilizes in the fourth decade [2]. Pediatric keratoconus $(<18$ years of age) is more progressive than in adults [3].Wollensak, 
et al, [4] introduced corneal collagen cross linking (CXL) in 2003 for treatment of keratoconus. In which they used riboflavin which is vitamin B2 in combination with ultraviolet A to form a new cross links on the surface of collagen fibrils, by this they

\section{Patients and Methods}

A prospective interventional case series study that was conducted in The Future Center for refractive surgery, Sohag, in the period from May 2017 to October 2018. The study included 50 eyes of 25 patients with keratoconus less than 18 years of age. The study had been approved by the Health Research Ethics Committee at Sohag Faculty of Medicine. Informed written consents were taken from the patients and their families after full explanation of this procedure for treatment of keratoconus and the nature of their disease. Diagnosis of keratoconus was based on clinical findings and corneal images generated by the (CSO, Florence, Italy). Exclusion criteria were as follows: Advanced

\subsection{Surgical procedure}

All the eyes were treated with accelerated trans-epithelial corneal crosslinking under topical or general anesthesia. CXL was performed under aseptic technique in the operating theatre under topical anesthesia eye drops or general anesthesia. Surgical field were prepared and eyelid speculum was inserted. Corneal epithelium was left intact. We used the KXL® System (Avedro Inc., USA) accelerated CXL protocol, riboflavin (Para Cel) dropped on the cornea every one and half minutes for 4.5 minutes. Then dropping of riboflavin (VibexXtra) every one and half minutes

\subsection{Statistical analysis}

Data was analyzed using SPSS. Quantitative data was represented as mean, standard deviation, median and range. Comparison was made between preoperative and postoperative follow up data at 3, 6, and 12 months using RMANOVA test. can increase the strength of the cornea and halting further progression [5]. This study aimed to assess the short term visual, refractive, and tomographic outcomes of CXL in patients $<18$ years of age.

keratoconus with keratometry values more than $60 \mathrm{D}$ and thinnest corneal thickness less than $400 \mu$ and history of previous corneal surgery. After the treatment, the patients were followed up for 12 months. At each follow-up visit, a standard examination was carried out to assess uncorrected distance visual acuity (UDVA), corrected distance visual acuity (CDVA), refractometry, keratometry, and corneal topography. The progression of keratoconus over 12 months was defined on the basis of following changes; 1) Change in either myopia and/or astigmatism of $\geq 3$ D. 2) Change in K-readings of $\geq 1.5$ D. 3) Corneal thickness decrease of $\geq 5 \%$.

for 6 minutes. Followed by 5.20 minutes accelerated CXL using the pulsed mode with $45 \mathrm{~mW}$ / CC power. The cornea was completely rinsed with balanced salt solution. Eyelid speculum removed. Postoperatively, Patients advised to refrain from eye rubbing. Antibiotic eye drops (e.g $0.3 \%$ moxifloxacin) and lubricants Hypromellose were advised for one week. Corticosteroids (e.g $1 \%$ Prednisolone acetate) eye drops were continued for two weeks. Bandage contact lens were applied and removed on first postoperative day.

Sphericity were examined using test of Sphericity. Fisher's Least Significant Difference (LSD) post hoc test to examine the difference at each time point. $\mathrm{P}$ value was considered significant if it was less than 0.05 . 


\section{Results}

The total number of patients included in this study was 50, with age range from 13 to 18 years old and mean age of $15.76 \pm 1.67$ years. 16 patients were males $(64.00 \%)$ and 9 patients were females (36.00\%), tab. (1).

Table (1) Patients' demographics

\begin{tabular}{|l|c|}
\hline \multicolumn{1}{|c|}{ Total number of study eyes } & $\mathbf{5 0}$ \\
\hline Total number of study patients & 25 \\
\hline Age: & \\
\hline Mean \pm SD & $15.76 \pm 1.67$ \\
\hline Median (Range) & $16(13-18)$ \\
\hline Gender: & \\
\hline Male & $16(64.00 \%)$ \\
\hline Female & $\left.9 \begin{array}{l}(36.00 \\
\%\end{array}\right)$ \\
\hline
\end{tabular}

\subsection{Visual acuity and refractive data}

The mean uncorrected visual acuity was $0.83 \pm 0.30 \log$ MAR at baseline and $0.74 \pm 0.33 \log$ MAR at 12 months with significant difference $(\mathrm{P}=0.009)$. Mean preoperative best-corrected visual acuity was $0.52 \pm 0.28 \log$ MAR, which improved to $0.31 \pm 0.27 \log$ MAR at 12 months with significant difference $(\mathrm{P}<0.0001)$, tab. (2). The mean preoperative spherical equivalent was $-4.69 \pm 4.48$ and showed a decrease

throughout the follow up period ending with mean value $-4.08 \pm 4.30$ at $12^{\text {th }}$ month with significant $\mathrm{p}$ value $(\mathrm{P}=0.003)$, the sphere value had a similar course: starting from a preoperative mean of $-3.17 \pm 3.95$ to $2.75 \pm 3.55$ at the end of follow up period with significant $\mathrm{p}$ value $(\mathrm{P}=0.01)$, the mean cylinder value was $-3.12 \pm 2.25$, These value was not significantly changed at $12^{\text {th }}$ month $(\mathrm{P}=0.052)$, tab. $(2)$.

Table (2) Visual acuity, in logarithm of the minimal angle of resolution units, spherical equivalent, Sphere and cylinder data (all reported as mean _ SD)

\begin{tabular}{|l|c|c|c|c|c|}
\multicolumn{2}{|c|}{ Preoperative } & $\begin{array}{c}\text { Postoperative } \\
\mathbf{3}^{\text {rd }} \text { month }\end{array}$ & $\begin{array}{c}\text { Postoperative } \\
\mathbf{6}^{\text {th }} \text { month }\end{array}$ & $\begin{array}{c}\text { Postoperative } \\
\mathbf{1 2}^{\text {th }} \text { month }\end{array}$ & P value \\
\hline UCVA & $0.83 \pm 0.30$ & $0.78 \pm 0.28$ & $0.73 \pm 0.30$ & $0.74 \pm 0.33$ & $\mathrm{p}=0.009$ \\
\hline BCVA & $0.52 \pm 0.28$ & $0.45 \pm 0.24$ & $0.36 \pm 0.23$ & $0.31 \pm 0.27$ & $\mathrm{p}<0.0001$ \\
\hline Sphere, D & $-3.17 \pm 3.95$ & $-2.86 \pm 3.37$ & $-2.8 \pm 3.55$ & $-2.75 \pm 3.55$ & $\mathrm{P}=0.01$ \\
\hline Cylinder, D & $-3.12 \pm 2.25$ & $-2.97 \pm 2.15$ & $-2.72 \pm 2.31$ & $-2.71 \pm 2.56$ & $\mathrm{P}=0.052$ \\
\hline SE,D & $-4.69 \pm 4.48$ & $-4.35 \pm 3.85$ & $-4.16 \pm 4.24$ & $-4.08 \pm 4.30$ & $\mathrm{P}=0.003$ \\
\hline
\end{tabular}

UCVA uncorrected distance visual acuity; $\boldsymbol{B C V A}$ best-corrected visual acuity; $\boldsymbol{D}$ diopter; $\boldsymbol{S D}$ standard deviation; $\boldsymbol{S E}$ spherical equivalent

\subsection{Tomography}

The tomographic data which was statistically analyzed in this study included the keratometry values and corneal thickness at thinnest location from preoperative to 3 months, 6 months and 12 months postoperative values. Mean baseline $\mathrm{K}_{1}$ (flattest $\mathrm{k}), \mathrm{K}_{2}$ (steepest $\mathrm{k}$ ) and $\mathrm{K}_{\text {average }}$ values were $44.48 \pm 2.73 \mathrm{D}, 48.31 \pm 3.92 \mathrm{D}, 46.07 \pm 2.87$ $\mathrm{D}$, respectively. There was no significant change in their mean values at 12 month which was $44.54 \pm 3.46 \mathrm{D}(\mathrm{P}=0.48), 48.15 \pm$ 3.99D $(\mathrm{P}=0.99), 46.16 \pm 3.24 \mathrm{D}(\mathrm{P}=0.96)$, respectively, tab. (3). There was no post- operative complications, such as chronic epithelial defects, haze, or infectious keratitis reported throughout the postoperative follow up period in the study population, one case show criteria of progression as at the end of the $12^{\text {th }}$ month the followings were noticed: 1) The cylinder increased from -7.00 to -10.50 , The flattest $\mathrm{K}$ increased from $55 \mathrm{D}$ to $59 \mathrm{D}, 2)$ The steepest $\mathrm{K}$ increased from $58 \mathrm{D}$ to $61 \mathrm{D}, 3$ ) The decision was to retreat this patient again with another session of corneal collagen cross-linking. 
Table (3) Tomographic measurements (mean \pm SD)

\begin{tabular}{|l|l|l|l|l|}
\multicolumn{2}{r|}{} & \multicolumn{2}{c}{ Preoperative } & \multicolumn{2}{c|}{$\begin{array}{c}\text { Postoperative } \\
\mathbf{3}^{\text {rd }} \text { month }\end{array}$} & $\begin{array}{c}\text { Postoperative } \\
\text { 6 }^{\text {month }} \text { month }\end{array}$ & P value \\
\hline K1, D & $44.48 \pm 2.73$ & $44.49 \pm 3.12$ & $44.54 \pm 3.46$ & $\mathrm{P}=0.48$ \\
\hline K2, D & $48.31 \pm 3.92$ & $48.15 \pm 3.91$ & $48.15 \pm 3.99$ & $\mathrm{P}=0.99$ \\
\hline K avg, D & $46.07 \pm 2.87$ & $46.17 \pm 3.23$ & $46.16 \pm 3.24$ & $\mathrm{P}=0.96$ \\
\hline Thickness at thinnest location, $\boldsymbol{\mu m}$ & $453.36 \pm 40.50$ & $445.4 \pm 39.80$ & $447.84 \pm 46.51$ & $\mathrm{P}=0.37$ \\
\hline
\end{tabular}

$\boldsymbol{K} 1$ flattest $k ; \boldsymbol{K} 2$ steepest $k ; \boldsymbol{K a v g}$, average $K . \boldsymbol{D}$, diopters; $\boldsymbol{S D}$, standard deviation. $\boldsymbol{P}$ value for change from baseline to 3 months, and to 6 months.

\section{Discussion}

It is known that typical onset of keratoconus is at puberty, but it does affect younger children. Léoni-Mesplié et al. conducted a large retrospective study, evaluating 216 keratoconic patients separated into various age groups and found that keratoconus in children was significantly more severe at diagnosis and progressed faster than in adults [6]. Since the progression of disease is more pronounced in young people than in elderly patients, cross-linking is particularly important for young patients. For example, the results of Vinciguerra's study suggest that the treatment effect could be more pronounced in young people than in older patients, whereby a mean reduction in maximum corneal refractive power of $1.27 \mathrm{dpt}$ was observed within 2 years following cross-linking in patients under 18 years of age [7]. Different studies compared the efficacy and safety of epithelial on collagen cross linking versus epithelial off technique in children, as Buzzonetti et al. in 2012, Salman et al. in 2016, and Eraslan et al in 2017 [8-9]. All reported the safety of both procedures, as regard the efficacy they showed that despite the efficacy of Epithelium on procedures it remains less effective than Epithelium off. In this study, we evaluated short-term visual, refractive, and tomographic outcomes of CXL in pediatric patients with keratoconus. The patients had been subjected to accelerated transepithelial corneal collagen cross linking with follow up period of twelfth months. In this study vision improved in most of patients from the first month postoperative and this improvement remained stable till the twelfth month, also there was improvement in the refractive indices with stability of the keratometric readings and a non-significant decrease in the thickness at thinnest corneal location. Derakhshan, et al, [11] reported improvement in UCVA and BCVA at $6^{\text {th }}$ month postoperative with significant reduction of the spherical equivalent and the keratometric readings. Tian M, et al. [12], also noticed improveement in vision after 1 year follow up with no significant difference in keratometric readings or in thinnest corneal thickness. Caporossi A, et al. [13], studied the effect of TE-CXL in progressive keratoconus in patients $<26$ years old for 24 months, results of the study showed that, an improvement in UDVA, although not statistically significant, was recorded at 6 months $(\mathrm{P}=0.13)$ and lasted until the $12^{\text {th }}$ month. At the 18 month follow up, the UDVA was worse, returning to baseline values $(\mathrm{P}=0.61)$. The worsening continued through 24 months $(\mathrm{P}=0.61)$, The CDVA increased starting from the first month until the sixth month postoperatively $(\mathrm{P}=0.18)$, it returned to preoperative values at 24 months $(\mathrm{P}=0.57)$ and similar to their finding regarding UCVA and BCVA, they reported initial improvement in Keratometric readings during the early periods of follow up then deterioration occurred and returned to the preoperative values, in 5 patients younger than 18 years, vision worsened significantly and were retreated with the epi-off CXL technique. In this study there was a slight decrease in the thickness of 
the thinnest location all over the follow up period, till the end of the $12^{\text {th }}$ month slight increase in thickness had been noticed with insignificant $\mathrm{P}$ value $=0.06$. This result also noted by Cinar Y, et al. [14], where the thickness of the thinnest location reduced significantly at $1^{\text {st }}$ month and regained its thickness at the $3^{\text {rd }}$ and $6^{\text {th }}$ month after CXL procedure. Decreased corneal thickness could be due to temporary increase in the pump activity of the endo- thelium which occurred due to hypoxic stress or UVA exposure and packing of the corneal lamellae due to formation of new cross-link [15]. No intraoperative or postoperative complications in patients were reported in the current study, indicating accelerated transepithelial (ATE-CXL) safety. Progression occurred only in one patient, Re-treatment was decided for the patient.

\section{Conclusion}

This study proved the efficacy and the safety of $c x l$ in pediatric population. Limitations to this study; short period of follow up and limited number of studied population.

\section{Acknowledgements}

I would like to thank Dr: Mortada Abo Zaid, Assistant professor of ophthalmology, faculty of medicine, Sohag University for his assistance that greatly improved the manuscript.

\section{References}

1. Rabinowitz Y. Keratoconus. Survey of Ophthalmology. 1998; 42: 297-319.

2. McMahon T., Edrington T., SzczotkaFlynn L., et al. Longitudinal changes in corneal curvature in keratoconus. Cornea 2006; 25: 296-305.

3. Ertan A., Muftuoglu O. Keratoconus clinical findings according to different age and gender groups. Cornea 2008; 27: 1109-1113.

4. Wollensak G., Spoerl E., Seiler T. Riboflavin/ultraviolet-a-induced collagen cross linking for the treatment of keratoconus. Am J Ophthalmol. 2003; 135: 620-627.

5. Hayes S., Kamma-Lorger C., Boote C., et al. The effect of riboflavin/UVA collagen cross-linking therapy on the structure and hydrodynamic behaviour of the ungulate and rabbit corneal stroma. PLoS One. 2013; 8: e52860.

6. Léoni-Mesplié S., Mortemousque B., Touboul D., et al. Scalability and severity of keratoconus in children. Am $\boldsymbol{J}$ Ophthalmol. 2012; 154: 56-62.e1.
7. Vinciguerra P., Albé E., Frueh B., et al. Two-year corneal cross-linking results in patients younger than 18 years with documented progressive keratoconus. Am J Ophthalmol. 2012; 154: 520-526.

8. Buzzonetti L, Petrocelli G. Transepithelial corneal cross-linking in pediatric patients: early results. J Refract Surg. 2012; 28: 763-767

9. Salman A. Corneal biomechanical and anterior chamber parameters variations after 1-year of transepithelial corneal collagen cross-linking in eyes of children with keratoconus. Middle East Afr J Ophthalmol. 2016; 23: 129-134.

10. Eraslan M., Toker E., Cerman E., et al. Efficacy of epithelium-off and epithetlium-on corneal collagen cross-linking in pediatric keratoconus. Eye Contact Lens. 2017; 43: 155-161.

11. Derakhshan A., Heravian J., Ahadi M., et al. Short-term outcomes of collagen crosslinking for early keratoconus. $\boldsymbol{J}$ Ophthalmic Vis Res. 2011; 6 (3): 155159. 
12. Tian M., Jian W., Sun L. One-year follow-up of accelerated transepithelial corneal collagen cross-linking for progressive pediatric keratoconus. $\boldsymbol{B M C}$ Ophthalmology. (2018) 18:75.

13. Caporossi A., Mazzotta C., Baiocchi S., et al. Transepithelial corneal collagen crosslinking for keratoconus: qualitative investigation by in vivo HRT II confocal analysis. Eur J Ophthalmol. 2012; 22 (7): S81-S88.
14. Cinar Y., Cingu A., Turkcu F., et al. Accelerated corneal collagen crosslinking for progressive keratoconus. Cutan Ocul Toxicol 2014; 33: 168- 171.

15. Holopainen J., Krootila K. Transient corneal thinning in eyes undergoing corneal cross-linking. Am J Ophthalmol. 2011; 152: 533-536. 